\title{
Strategi Komunikasi Bisnis OYO Hotels and Homes Indonesia Di Masa Pandemi Covid-19 Melalui Program Sanitized Stays
}

\author{
Gan Gan Giantika
}

Universitas Bina Sarana Informatika

Email : gan.ggt@bsi.ac.id

\author{
Cara Sitasi: Gan Gan G (2021) Strategi Komunikasi Bisnis OYO Hotels and Homes Indonesia Di Masa \\ Pandemi Covid-19 Melalui Program Sanitized Stays, 2021 21(2), 116-121 Retrieved from \\ https://doi.org/10.31294/jc.v19i2
}

\begin{abstract}
The hotel industry is one of the industries that has a major contribution to the Indonesian economy. The COVID-19 pandemic, which has been ongoing since early 2019, has had a negative impact on various industries, including the hotel industry. Indonesia is one of the regions in the world affected by COVID-19. The hotel industry has experienced a very drastic decline in occupancy, therefore it is necessary to implement an appropriate and effective business communication strategy in order to stabilize the declining occupancy. The purpose of this research is to find out how the business communication strategy implemented by OYO Hotels and Homes Indonesia during the Covid-19 Pandemic through the Sanitized Stays Program. The method used in this research is descriptive qualitative method by collecting factual data based on observations, and documentation and literature relevant to this research. The results of the research and the conclusion that OYO Hotels and Homes Indonesia carried out business communication strategy activities through the Sanitized Stays program were in accordance with the objectives of the hotel, namely stabilizing occupancy during the Covid-19 pandemic.
\end{abstract}

Keywords : Strategy, Communication, Business, Sanitized Stays Program

\section{PENDAHULUAN}

Pada Tahun 2019 sebuah organisani Kesehatan Dunia atau yang kita kenal dengan isitilah World Health Organization biasa disingkat dengan WHO mengumumkan ke seluruh dunia adanya pandemi global tentang Covid-19. Maka seluruh dunia termasuk Indonesia juga turut merasakan dampak dari wabah Covid - 19 .

Pada tahun 2019 di Wuhan, Hubei, China ditemukan penyakit coronavirus jenis baru atau yang dikenal dengan istilah COVID- 19. Akhirnya diberbagai penjuru dunia mengalami dampak penyakit baru ini. Penularannya melalui saluran atau sindrom pernapasan yang cukup akut dengan istilah coronavirus 2 (severe acute respiratory syndrome coronavirus 2 atau SARS-CoV-2) (Amri, 2020).

Dengan adanya kejadian wabah ini sangat memberikan efek yang sangat berdapak pada pertumbuhan terhadap dunia bisnis, salah satunya adalah bisnis Startup jaringan hotel. Hal ini pula sangat dirasakan dampaknya pada Bisnis OYO Hotels and Homes Indonesia.

Penyedia akomodasi dalam hal menyediakan pelayanan jasa seperti penginapan, atau menyediakan makanan dan minuman serta menyediakan fasilitas berupa ruangan (rooms) untuk disewakan kepada masyarakat atau pengunjung dengan membayar sesuai tarif yang telah ditetapkan oleh perusahaan maka hal ini disebut dengan Hotel. (Sujana, 2015)
OYO Hotels and Homes mulai mengawal bisnisnya pada tahun 2013 dan merupakan sebuah startup hotel yang hingga saat ini memiliki banyak cabang atau jaringan di seluruh dunia. OYO Hotels and Homes memiliki sistem yang dikembangkan seperti sebuah rumah dalam bentuk real estate. atau town house (Kontan.co.id, 2021).

PT Oyo Rooms Indonesia merupakan badan hukum yang berdiri di Indonesia sejak Februari 2018. Sebelumnya pihak OYO melakukan riset terlebih dahulu mengenai situasi dan kondisi pangsa pasar dan peraturan yang harus dilaksnankan, barulah setelah riset maka diputuskan untuk membuka cabang di Indonesia.

Setelah melihat kondisi pasar yang menjanjikan dan menguntungkan maka Startup unicorn asal India OYO ini mulai Kamis, 18 Oktober 2018 hadir di Indonesia. Sejak saat itulan OYO terus mengembangkan bisnisnya dengan mitra yang berjumlah sekitar tiga puluh saling bekerjasama. Kerja sama ini juga dilakukan dengan pengusaha yang beregrak dalam bisnis perumahan dan ada kurang lebih seribu rooms yang berada di berbagai wilayah seperti Jakarta, Surabaya, dan Palembang. (Kontan.co.id, 2021)

Selama berlangsungnya pandemi Covid-19 OYO Indonesia mengalami dampak pada tingkat pendapatan hotel yang cukup menurun. Penurunan pendapatan ini hingga mencapai 60 persen. Apalagi sejak diberlakukannya. Pembatasan Sosial Berskala Besar (PSBB) yang ditetapkan oleh Pemerintah yang diterapkan di berbagai daerah di Indonesia 
menyebabkan tersendatnya laju perekonomian khususnya pada tingkat hunian hotel.

Hal ini seperti diungkapkan oleh (Sujana, 2015) bahwa sejak dicanangkan pada tanggal 31 Maet 2020 oleh Pemerintah tentang Social Distancing atau menjaga jarak sosial hal ini memberikan dampak serius terhadap tingkat okupansi hotel.

Seperti diungkapkan Eko Bramantyo selaku Country Head Emerging Business OYO Hotels and Homes Indonesia. "efeknya ini paling berasa saat Mei lalu yaitu setiap hari tingkat kunjungan atau hunian kita selalu mengalami penurunan. Dalam mengatasi masalah ini, kita akan memikirkan dan menyelesaikan masalah ini”. (Ningsih, 2020).

Adaptasi terhadap protokol kesehatan menjadi hal yang sangat penting dan strategi komunikasi bisnis sangat diperlukan bagi kebangkitan bisnis akomodasi selama pandemi Covid-19.

Setiap perusahaan dalam menjalankan bisnisnya mempunyai strategi yang telah disusun dengan baik salah satunnya dengan mendukung aktivitas perusahaan. Langkah yang akan diambil akan dikondisikan dengan situasi dan kondisi baik dari segi masyarakat maupun situasi ekonomi. Langkah ini merupakan sebuah strategi atau cara mengenai program yang bertujuan mendukung majunya bisnis perusahaan.

Pernyataan Candler seperti dikutip oleh (Rangkuti, 2008) strategi sebuah rencana atau disebut program yang akan datang dan merupakan tindak lanjut, juga merupakan skala prioritas dalam mengalokasikan sumber daya.

(Rangkuti, 2008) ) mengutip pernyataan Hamel dan Prahalad bahwa sebuah perbuatan atau tindakan dapat meningkat disebut juga dengan sebutan incremental, tindakan ini dilakukan dengan memperhatikan kebutuhan yang diharapkan oleh konsumen secara berkala dan inilah yang dinamakan strategi. Untuk mewujudkan strategi harus ada sebuah inovasi dan yang paling utama memperhatikan kondisi pasar serta perubahannya agar dapat terus mengikuti perkembangan dan memenuhi kebutuhan pelanggan. Hal ini terjadi karena perubahan metode dan cara pelanggan mmebutuhkan persaingan dalam kompetensi inti atau(come competencies dengan dipengaruhi kecepatan inovasi pasar yang baru.

(Umar, 2005) mengutip pernyatan Marrus dalam mendefinisikan kata strategi bahwa ini adalah suatu tahap dalam mencapai tujuan jangka panjang dalam menentukan sebuah rencana yang berasal dari puncak pimpinan agar segala tujuan yang telah direncanakan dapat terwujud.
Komunikasi memiliki kata communication dalam bahasa Inggris, dan juga bersumber dari kata communis dari Bahasa Latin yang memiliki makna yaitu 'sama'.

Kata 'sama' ini memiliki kesamaan dalam makna atau sama makna. Hafied Cangara juga mengungkapkan bahwa kata komunikasi merupakan pangkal dari Bahasa Latin yaitu kata communis yang berarti adalah sebuah kebersamaan yang terdiri dari dua orang bahkan lebih. (Cangara, 2014)

Menurut Everett M.Rogers dalam (Mulyana, 2014) "Proses dalam sebuah ide yang bersumber dari penerima atau komunikan dapat satu komunikan/ penerima atau lebih dan dengan tujuan untuk mengubah cara/prilaku merupakan arti dari Komunikasi"

Definis Bisnis adalah kegiatan menjual barang atau jasa kepada konsumen atau bisnis lainnya yang dilakukan suatu organisasi dengan tujuan memperoleh keuntungan atau hasil yang maksimal. Ungkapan bisnis dari Bahasa Inggris yaitu business, dan memiliki konteks secara individu, komunitas maupun masyarakat adalah "sibuk". Sibuk disini merupakan istilah adanya aktivitas atau kegiatan yang bertujuan mendapatkan profit atau keuntungan. (Jones \& Lindawaty, 2007).

Bisnis untuk mendapatkan profit dengan mengadakan tersedianya produk yang dibutuhkan oleh orang lain dan dilakukan seseorang bahkan dilakukan lebih dan dilaksanakan secara terorganisasi. (Tantri, 2009).

\section{METODOLOGI PENELITIAN}

Penelitian yang digunakan adalah peneltian kualitatif yang dilaksanakan pada situasi alamiah dan bersifat penemuan. Peran peneliti sebagai instrument kunci. Maka dari itu peneliti harus memiliki bekal teori dan wawasan yang luas sehingga dapat bertanya, menganalisis dan mengkonstruksi objek yang dilteliti menjadi lebih jelas. Penelitian ini lebih menekankan pada makna dan terikat nilai.

Seperti yang diungkapkan oleh Bogdan dan Taylor dalam (Moleong, 2016) "Prosedur penelitian yang menghasilkan data deskriptif berupa kata-kata tertulis atau lisan dari orang-orang dan perilaku yang dapat diamati termasuk ke dalam metodologi penelitian kualitatif."

Untuk memahami fenomena tentang apa yang dialami oleh subjek penelitian merupakan penelitian kualitatif, contohnya perilaku, pendapat, dorongan/motivasi serta sebuah kegiatan atau 'tindakan', dll. Dalam bentuk kata-kata dan bahasa secara holistik dapat di deskripsikan dengan aturan yang dengan menggunakan 
suatu konteks yang khusus secara alamiah dan dengan memanfaatkan berbagai metode atau cara alamiah. (Moleong, 2016).

\section{HASIL DAN PEMBAHASAN}

Dalam memaksimalkan lini bisnisnya, saat ini OYO fokus dalam meningkatkan teknologi dengan prosedur serta merumuskan prosedur tersebut yang sesuai dengan New Normal. Hal ini diterapkan baik secara akomodasi maupun non akomodasi agar bisnis yang dijalankan tetap berjalan dan relevan dengan kebutuhan masyarakat baik dimasa pandemi maupun setelah pandemi berakhir.

Country Head OYO Indonesia, Bapak Agus Hartono Wijaya mengungkapkan bahwa "masa pandemi ini OYO terus melihat perkembangan dunia bisnis perhotelan agar mampu bertahan dan terus melakukan rangkaian inovasi. OYO dapat melalui masa pandemi ini dengan beragam strategi yang disesuaikan dengan kondisi serta kebutuhan masyarakat seperti menjamin terjaganya sistem dalam segi kesehatan, kemananan serta kenyamanan para pengunjung yang menginap di OYO. (Kontan.co.id, 2021).

Dalam mewujudkan dan memulihkan tingkat okupansi OYO, maka pihak OYO membuat strategi dengan rangkaian inovasi melalui program yang di beri nama 'Sanitized Stays '. Program 'Sanitized Stays' merupakan strategi yang terdiri dari tujuh rangkaian strategi dengan tujuan untuk meningkatkan bisnis OYO dalam masa pandemi maupun meningkatkan bisnis dalam jangka Panjang mengutamakan keselamatan, kesehatan serta kenyamanan bagi para tamu OYO.

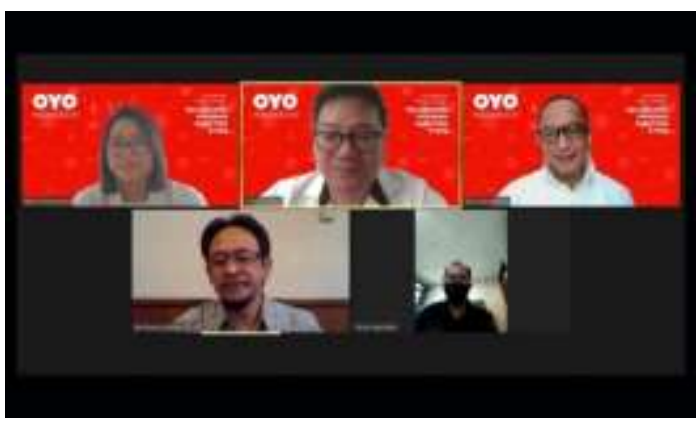

Sumber : (Republika.co.id, 2020)

Gambar 1. OYO Luncurkan Sanitized Stay di Indonesia

Program 'Sanitized Stays' dilakukan pada masa pandemi ini dalam proses operasional hotel dari awal check-in dan check-out dengan menerapkan protokol kesehatan yang tinggi serta menjunjung tingga rasa nyaman konsumen, sehingga mitra OYO terus menjalankan bisnisnya dengan lancar.

Selaku Country Head Emerging Business, Bapak Eko Bramantyo, "adanya pandemi seluruh dunia memberikan dampak yang cukup sulit bagi OYO Hotels and Homes Indonesia dan ini cukup merubah sistem dengan menciptakan pola dan strategi. Dengan wabah ini banyak perubahan dalam industri perhotelan baik dari menurunnya jumlah tamu dan juga harus adanya perubahan dalam segi pelayanan". (Henry, 2020)

"Program kualifikasi 'Sanitized Stays' ini, ada standar baru yang akan kami terapkan guna mengurangi kontak fisk atau sosial disntancing pada aktivitas operasional OYO dan juga mitra hotel OYO. Pada program 'Sanitized Stays' ini akan diterpakan aturan serta protokol sesuai dengan ketetapan yang telah ditentukan oleh pemerintah.

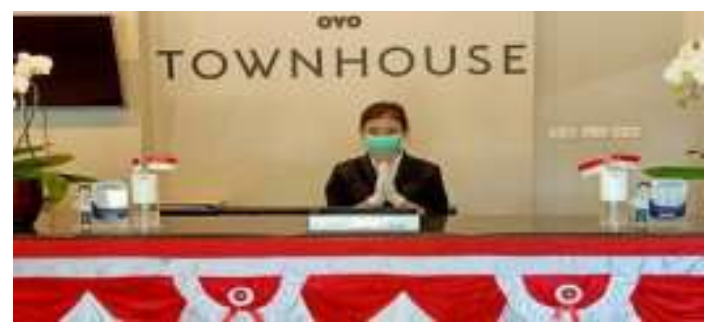

Sumber : (indotelko.com, 2021)

\section{Gambar 3. Tampilan Ruang Resepsionis OYO} Dengan Menerapkan Protokol Kesehatan

Program kualifikasi Sanitized Stays adalah bagian strategi dalam masa pandemi Covid-19 serta dalam menghadapi masa "the new normal".

Program kualifikasi Sanitized Stays yang pertama adalah Lingkungan Higienis. Pada program ini seluruh kamar (rooms) OYO akan dilakukan desinfeksi atau mensterilkan serta membersihkan dilakukan secara berkala terutama terhadap ruangan yang merupakan area umum dan sering adanya kontak fisik seperti handle pintu.

Program kualifikasi Sanitized Stays yang kedua adalah Keamanan Tamu. Pada program ini OYO akan menyediakan masker atau penutup wajah bagi tamu hotel dan selalu memastikan hand sanitizer di ruangan yang di kunjungi tamu.

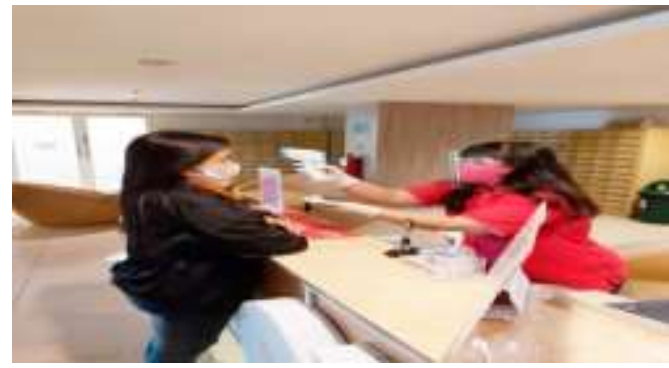

Sumber : (Republika.co.id, 2020) 
Gambar 4 : Penerapan Protokol Kesehatan di OYO

Program kualifikasi Sanitized Stays yang ketiga adalah Keamanan Staf. Pada tahap ini OYO, untuk kesehatan dan keselamatan karyawan akan selalu menyediakan alat pelindung diri seperti seragam Personal Protective Equipment, menyediakan masker dan hand sanitizer.

Program kualifikasi Sanitized Stays yang keempat adalah Kontak Fisik Minimal. Pada rangkaian strategi ini pihak OYO akan melakukan kegiatan kontak fisik seminimal mungkin. mulai dari check-in hingga check-out dengan kontak fisik yang minimal (less physical contact).

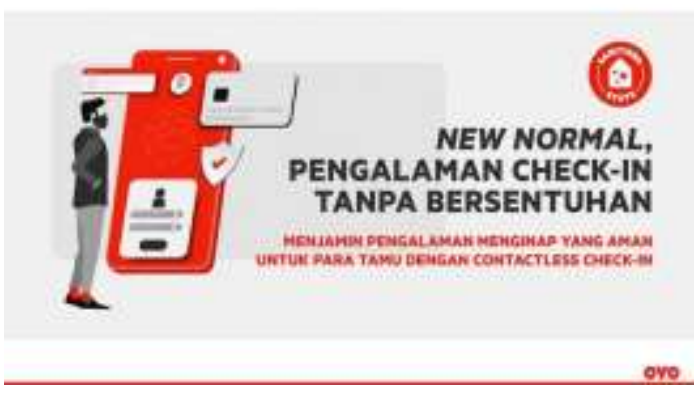

Sumber : (Republika.co.id, 2020)

\section{Gambar 5 : Penerapan Protokol Kesehatan di OYO}

Program kualifikasi Sanitized Stays yang kelima adalah Staf yang terlatih. Pada program ini OYO akan mengadakan training bagi staff dan seluruh tim yang bertugas dilapangan mengenai prosedur dan regulasi terkait protokol kesehatan di masa pandemi.

Program kualifikasi Sanitized Stays yang keenam adalah Penerapan Social Distancing. Mengikuti instruksi pemerintah agar menerapkan social distancing. Dalam melakukan aktivitas seluruh staf dan tamu hotel akan menjalankan social distancing selama berada di area dan lingkungan hotel secara maksimal.

Program kualifikasi Sanitized Stays yang ketujuh adalah Saluran Bantuan Darurat dan Rute Rumah Sakit Terdekat. Pada program ini mengadakan koordinasi dengan pihak rumah sakit terdekat untuk mengantisipasi penanganan dari tenaga medis atau yang berhubungan langsung ke rumah sakit.

Bapak Carlo Ongko selaku Country Stock Head OYO Hotels and Homes Indonesia mengatakan (Annur, 2020):

"Strategi awal atau pertama yaitu strategi Lingkungan Higienis merupakan langkah dalam memotivasi mitra hotel OYO agar menjalankan dan melaksanakan pembatasan fisik atau social distancing dengan taan dan tertib. " penerapan jaga jarak fisik secara maksimal akan kami lakukan secara maksimal di lingkungan hotel dan berlaku bagi karyawan maupun tamu OYO.

Kedua adalah Keamanan Tamu, pada langkah ini kami akan melakukan pemberian materi serta pelatihan bagi para seluruh karyawan. Training akan memenuhi prosedur yang sesusi dengan Prokes (Protokol Kesehatan) dengan prosedur sesuai standarisasi seperti kenyamanan, kesehatan, sanitasi, dan keselamatan pada masa pandemi ini.

Keamanan Staff adalah strategi yang ketiga, Mitra hotel OYO diwajibkan melakukan pembersihkan secara steril dalam lingkungan hotel baik dari kamar dan area hotel yang lain, terutama area yang sering adanya kontak fisik.

Pada startegi yang keempat adalah Kontak Fisik Minimal, hal ini akan dimulai dari para tamu check-in hingga check-out. OYO membuat sebuah fitur untuk para tamu yang baru checkin untuk mengurangi kontak (Contactless) yaitu dengan inovasi scan QR code dan menunjukkan Kartu Tanda Penduduk (KTP) sebagai verifikasi identitas. Sehingga penerapan zero touch policy.dapat terlaksana.

Staf yang terlatih adalah strategi yang kelima, untuk menjamin rasa nyaman para tamu pihak OYO akan menyediakan masker atau penutup wajah. Serta ketersediaan hand sanitizer yang akan ditempatkan pada area yang sering dikunjungi tamu.

Keenam yaitu Penerapan Social Distancing, tentu saja dengan selalu menjaga jarak sehingga staff yang bertugas akan terlindungi keamanan dan kesehatannya. Selain itu OYO juga akan menyediakan masker serta hand sanitizer dan juga seragam atau pakaian yang dikenakan adalah berupa Personal Protective Equipment yang berfunsi sebagai alat melindungi diri bagi staff yang sedang bertugas.

Ketujuh Saluran Bantuan Darurat dan Rute Rumah Sakit Terdekat. Pada strategi yang terakhir pihak OYO akan menyediakan dan berkoordinasi dengan pihak rumah sakit yang tidak jauh dengan lokasi hotel OYO. "kami harus berkoordinasi dengan rumah sakit untuk mengantisipasi dalam mengutamakan keselamatan dan kesehatan pelanggan dan ini sudah di sosialisasikan kepada seluruh mitra OYO." 


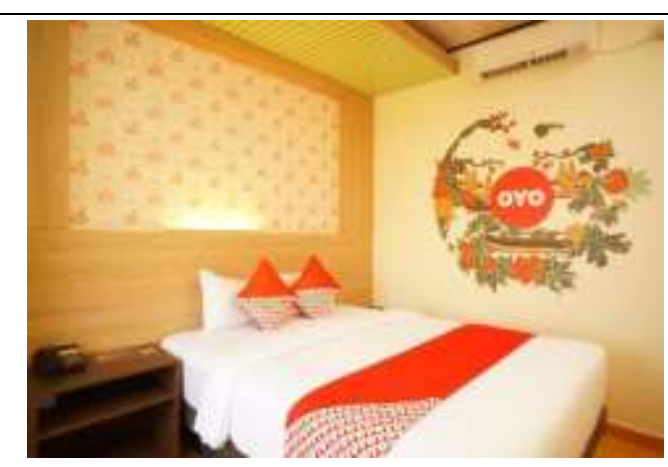

Sumber : (Henry, 2020)

Gambar 6. Salah satu kamar hotel OYO

OYO Hotels and Homes Indonesia akan memastikan bahwa setiap tamu yang datang dan menginap di OYO akan merasa nyaman dan terjamin keselamatan daan kesehatannya dan ini adalah rangkaian bentuk strategi yang dilakukan melaui program Sanitized Stays.

Kolaborasi yang kuat dan inovatif antar mitra hotel OYO merupakan kunci dalam kesuksesan menjalankan operasional hotel OYO Indonesia dalam mempertahankan dan menjalankan usaha bisnis perhotelan terutama dalam masa pandemi Covid-19. Hingga saai ini OYO terus membuktikan bahwa mampu maju dengan memiliki kamar sekitar 350 ribu rooms yang tersebar di berbagai cabang di dunia sedangkan di Indonesia memiliki sekitar 45 ribu rooms.

OYO dapat membuktikan bahwa mampu melewati dampak pandemi dengan peningkatan jumlah tamu hotel mencapai sekitar $85 \%$ dari periode sebelum adanya pandemi. Serta di ikuti dengan tingkat performa sebesar $6 \%$ dan ini adalah wujud nyata keberhasilan dari strategi yang dilakukan melalui program Sanitized Stay. (indotelko.com, 2021).

\section{KESIMPULAN}

Strategi komunikasi bisnis OYO Hotels and Homes Indonesia dilakukan untuk mempertahankan kelangsungan usaha Industri perhotelan di tengah pandemi Covid-19 ini. Dalam mewujudkan program Sanitized Stays diperlukan strategi yang matang dan inovasi yang handal serta teknologi agar menunjang langkah dan tujuan yang akan dicapai oleh Bisnis OYO Hotels and Homes Indonesia.

Penerapan strategi Program Sanitized Stays memiliki dampak positif bagi OYO Hotels and Homes Indonesia. OYO Hotels and Homes Indonesia dapat meningkatkan jumlah hunian dan menjadikan hotel dengan mengutamakan standar Protokol Kesehatan yang baik dengan mengedapankan rasa nyaman para tamu hotel. Sehingga program Sanitized Stays mampu meciptakan keuntungan bagi daari segi laba maupun dari sisi terjaminnya keselamatan dan kesehatan masyarakat.

\section{REFERENSI}

Amri, A. (2020, Juni 1). Dampak COVID-19 Terhadap UMKM Di Indonesia. Jurnal Brand, Volume 2 Nomor 1 Juni 2020.

Annur, C. M. (2020, Juni 11). https://katadata.co.id. Retrieved Mei 28 2021,https://katadata.co.id/agustiyanti/digit al/5ee1dec637fca/bisnis-anjlok-imbaspandemi-oyo-ungkap-strategi-sambutnormal-baru

Cangara, H. (2014). Perencanaan \& Strategi Komunikasi. In Edisi Revisi. Jakarta: PT.Rajagrafindo Persada.

Henry. (2020, Juni 11). www.liputan6.com. Retrieved Mei 28, 2021, https://www.liputan6.com/lifestyle/read/42 76783/7-strategi-oyo-untuk-berikan-rasaaman-menginap-selama-pandemi

indotelko.com. (2021, Maret 21). Retrieved Mei 28, 2021, from OYO bertahan selama pandemi, kuncinya kepercayaan mitra: https://www.indotelko.com/read/16168084 80/oyo-bertahan-selama-pandemikuncinya-kepercayaan-mitra

Jones, I., \& Lindawaty, S. (2007). Hukum Bisnis Dalam Persepsi Manusia Modern. Bandung: PT Refika Aditama.

Kontan.co.id. (2021, February 8). https://pressrelease.kontan.co.id/release/ter us-beradaptasi-hadapi-pandemi-oyoindonesia-fokus-ke-safecation-di2021 ? page $=$ all. Retrieved Mei 28, 2021

Moleong, L. J. (2016). Metodologi Penelitian Kualitatif. Bandung: Remaja Rosdakarya.

Mulyana, D. (2014). Ilmu Komunikasi: Suatu Pengantar. In Cetakan ke 18. Bandung: PT. Remaja Rosdakarya.

Ningsih, B. (2020, Juni Senen). https://venuemagz.com/hotel/strategi-oyotingkatkan-bisnis-kembali/. Retrieved Mei 26, 2021

Rangkuti, F. (2008). Analisis SWOT : Teknik Membedah Kasus Bisnis. Jakarta: Gramedia Pusaka Utama. 
Republika.co.id. (2020, Juni 12). https://republika.co.id. Retrieved Mei 28, 2021,

https://republika.co.id/berita/qbrnz6651700

0/masuk-new-normal-oyo-luncurkansanitized-stay-di-indonesia

Sujana, E. (2015). Pengaruh Karakteristik Informasi Sistem Akuntansi Manajemen (Sam), Desentralisasi, Dan Ketidakpastian Lingkungan Terhadap Kinerja Manajerial (Studi Empiris Pada Hotel Se-Kabupaten Buleleng). Journal Akuntasi, 3 No. 1 (https://doi.org/https://doi.org/10.23887/jim at.v3i1.5121).

Tantri, F. ( 2009). Pengantar Bisnis. Jakarta: Rajawali Pers.
Umar, H. (2005). Strategic Management In Action. Jakarta: PT Gramedia Pustaka Utama.

\section{PROFIL PENULIS}

Gan Gan Giantika, M.M., M.I.Kom. Sejak tahun 2008 bergabung di Universitas Bina Sarana Informatika sebagai Dosen. Telah menempuh Strata Dua (S2) di Universitas Bina Sarana Informatika Bandung dengan Program Magister Manajemen. Pada April 2021 telah berhasil menyelesaikan Pendidikan Program Studi Magister Ilmu Komunikasi di Universitas Sahid Jakarta. 